\title{
PROJETO DE CESSÃO DE BOMBEIROS MILITARES PARA ATUAREM NAS COORDENADORIAS MUNICIPAIS DE PROTEÇÃO E DEFESA CIVIL ONDE HAJA FRAÇÃO BOMBEIRO MILITAR INSTALADA
}

Kleber Silveira de Castro ${ }^{1}$

\section{RESUMO}

Este artigo científico empírico utiliza-se da metodologia da Matriz do Marco Lógico para propor um projeto de cessão de bombeiros militares para trabalharem junto às coordenadorias municipais de Proteção e Defesa Civil onde haja fração bombeiro militar instalada, crendo que a presença de um assessor estadual militar pode potencializar as ações de prevenção, mitigação, preparação, resposta e recuperação em desastres no nível municipal, considerando a alta capacitação técnica dos bombeiros militares em sua formação acadêmica e atuação profissional. Com a utilização da ferramenta Matriz do Marco Lógico foram identificados problemas na gestão de Proteção e Defesa Civil e ainda utilizando a mesma ferramenta foi proposto o desdobramento de ações a serem desempenhadas pelo bombeiro militar como assessor estadual militar em um município, cumprindo o disposto em normas legais brasileiras e acordo internacionais para redução do risco de desastres. Verificou-se que a cessão de cerca de $2 \%$ do total do efetivo do Corpo de Bombeiros Militar de Minas Gerais pode, mesmo com baixo impacto nas alas operacionais, apresentar grande impacto na prevenção e ações de mitigação com gestão proativa de Proteção e Defesa Civil.

Palavras-chave: Proteção e Defesa Civil; Cessão de Bombeiro Militar; Matriz Marco Lógico; Gestão do Risco de Desastre.

\footnotetext{
${ }^{1}$ Major do Corpo de Bombeiros Militar de Minas Gerais. Email: kleber1979castro@gmail.com
} 


\title{
DESIGN OF ASSIGNMENT OF MILITARY FIRE FIGHTERS TO ACT IN MUNICIPAL COORDINATORS OF CIVIL PROTECTION AND DEFENSE WHERE THE MILITARY FIRE FIGHTER HAS BEEN INSTALLED
}

\begin{abstract}
This empirical scientific article uses the Logical Framework methodology to propose a project for the assignment of military firefighters to work with municipal Civil Defense and Protection coordinators where there is a military firefighter fraction installed, believing that the presence of a state military advisor it can enhance the actions of prevention, mitigation, preparation, response and recovery in disasters at the municipal level, considering the high technical capacity of military firefighters in their academic training and professional performance. With the use of the Logical Framework tool, problems in the management of Civil Defense and Protection were identified and, still using the same tool, it was proposed the deployment of actions to be performed by the military firefighter as a state military advisor in a municipality, complying with the provisions of norms Brazilian legal frameworks and international agreements for disaster risk reduction. It was found that the transfer of about $2 \%$ of the total staff of the Military Fire Department of Minas Gerais can, even with a low impact on the operational wings, have a great impact on prevention and mitigation actions with proactive management of Civil Defense and Protection .
\end{abstract}

Keywords: Civil Defense and Protection; Military Firefighter Assignment; Logical Framework Matrix; Disaster Risk Management. 


\section{INTRODUÇÃO}

Proteção e Defesa Civil é a atividade de proteção à vida e a redução do risco de desastres e reestabelecimento da moral da população. Um grande desafio da atualidade é desenvolver comunidades mais resilientes, criando uma maior conscientização e prática para a redução de desastres (UN-ISDR, 2015). A Carta Magna de 1988 determinou aos corpos de bombeiros militares em seu artigo 144 a "execução de atividades de defesa civil". O Corpo de Bombeiros Militar de Minas Gerais (CBMMG) está presente em 76 municípios mineiros, com instalações de Batalhões, Companhias Independentes, Companhias e Pelotões e Posto Avançados nesses diferentes municípios (CBMMG, 2021).

Recentemente a Lei Federal 12.608/2012 apresentou como diretriz a execução municipal de ações de prevenção aos desastres, pois é nas cidades que moram os cidadãos e onde os desastres acontecem, através de suas Coordenadorias Municipais de Proteção e Defesa Civil (COMPDECs). Uma das alternativas a este cenário é a possibilidade de ceder bombeiros militares para atuarem nas Coordenadorias Municipais de Proteção e Defesa Civil, que pode acontecer por iniciativa do alto comando do CBMMG ou por parte dos interessados em nível de município e até mesmo de ambas as partes. Essa hipótese foi encarada vislumbrando que o impacto no efetivo pode ser pequeno frente ao impacto operacional, desde que observado um critério adequado, que seja exequível pela Corporação - considerando o tipo de fração BM esteja instalada, versus os resultados de um trabalho integrado de cooperação entre COMPDECs e a instituição secular dos combatentes do fogo em Minas Gerais.

Esse estudo verificou normativas legais sobre Proteção e Defesa Civil, com utilização da metodologia do Marco Lógico (PFEIFER, 2014), propondo que que o CBMMG ceda bombeiros militares do serviço ativo para atuarem nas COMPDECs, uma vez que esses militares são preparados profissionalmente 
para isso (conforme disciplinas constantes dos cursos de formação profissional) e que possuem experiência e capacidade de agir de forma organizada, padronizada e visando padronizar as ações preventivas de forma homogênea em todo Estado de Minas Gerais.

\section{REFERENCIAL TEÓRICO}

Como o Marco Lógico foi uma ferramenta desenvolvida pela Agência dos Estados Unidos para o Desenvolvimento Internacional (USAID) para melhorar o planejamento de intervenções e aumentar a capacidade de sucesso de projetos, foi escolhida por dar liberdade nas proposições de ações: desde a identificação de problemas, de suas causas, suas consequências e então buscando-se sua solução, com meios e fins para isso. Assim, buscou-se utilizar o quadro de estrutura do Marco Lógico para explicitar os objetivos específicos, que são determinar as ações (GUERESI, 2016) para que os bombeiros militares cedidos às COMPDECs devem cumprir para efetivar sua atuação.

A árvore de problema é um poderoso auxílio para organizar as informações e apresenta um modelo lógico de diagnóstico: em sua base, representadas pelas raízes inicia-se com as CAUSAS que geram o problema; no troco deve-se colocar o PROBLEMA (principal e único) que se busca resolver; nas folhas e galhos deve-se listar as CONSEQUÊNCIAS, direcionadas de acordo com causas/problemas, podendo haver desdobramentos das causas. Da mesma forma, nas consequências podem haver outros ramos para se verificar consequências das consequências, como apresentado na figura 1 : 


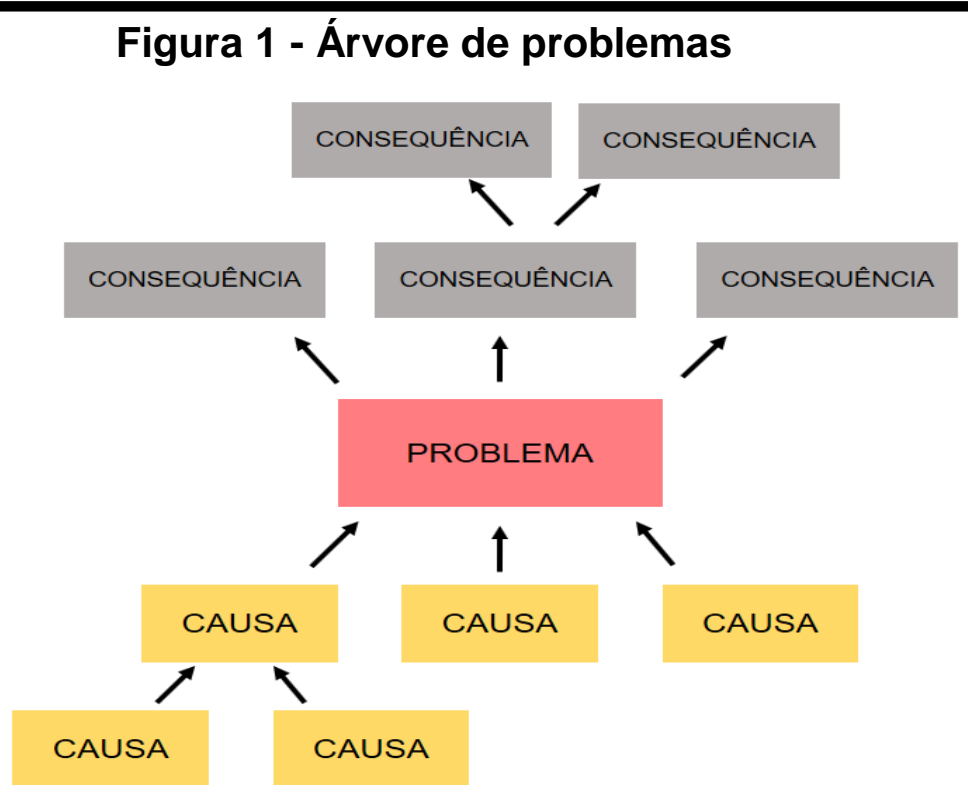

Fonte: o autor, adaptado de RUA (2000)

Assim, pode-se trabalhar na proposição de soluções, de uma árvore de objetivos, que tenham ações ou produtos diretamente relacionados às causas, para então eliminar o problema e que possam produzir diferentes consequências, chamadas então de objetivos:

Figura 2 - Árvore de objetivos

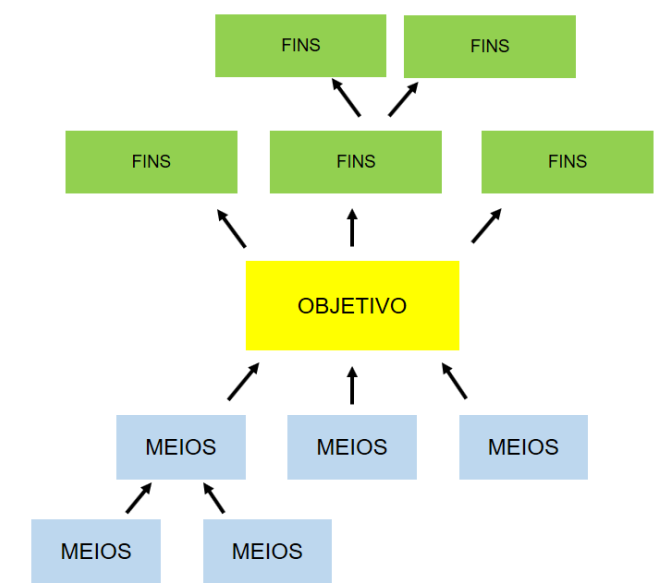

Fonte: adaptado de RUA (2000) 


\section{DESENVOLVIMENTO}

Como a atuação de Proteção e Defesa Civil (PDC) acontece onde as pessoas vivem, é fundamental reconhecer o local onde será aplicado o esforço de estudo, reconhecimento, planejamento e aplicação de recursos humanos e materiais para a redução de desastres. Destaca-se a geotopografia variada de Minas Gerais (SAADI, 1995), onde pode-se encontrar serras com altos morros - inclusive com o terceiro maior pico do Brasil - até sertões áridos e hostis, passando por planaltos de altitude, outros locais de abundância de recursos hídricos, já outros com seca quase perene.

\section{Gráfico 1 - Presença do Corpo de Bombeiros Militar em municípios mineiros}

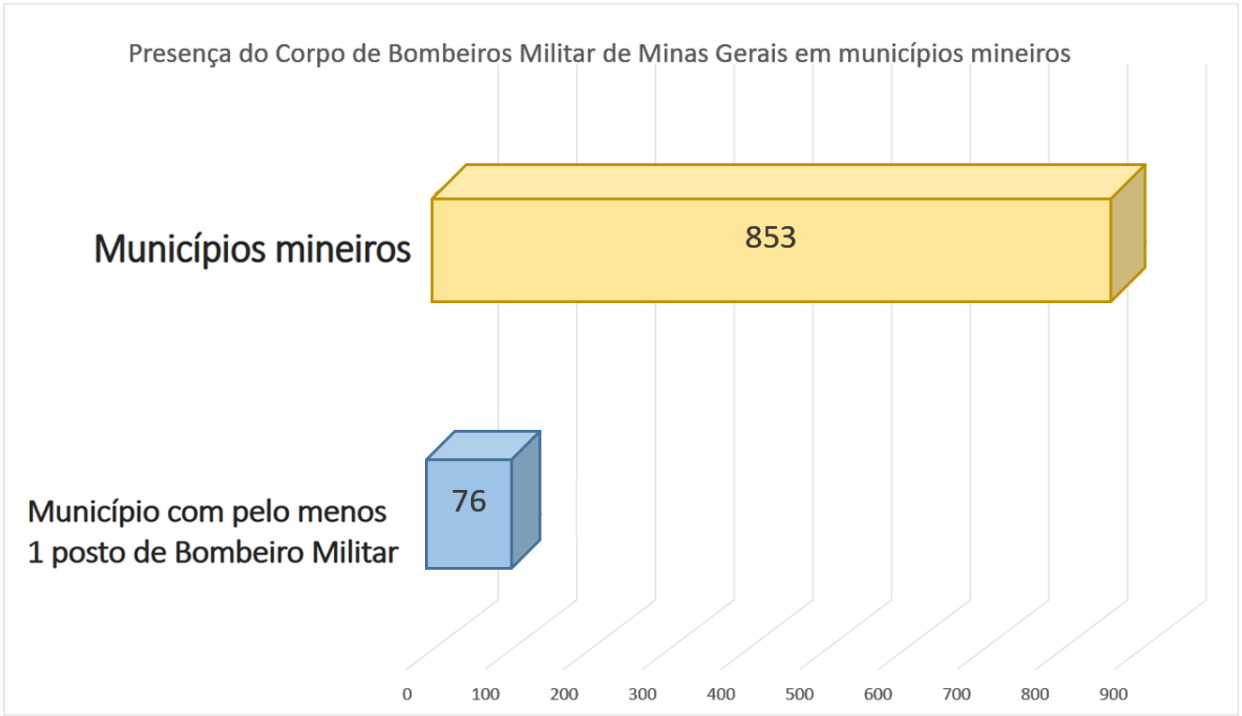

Fonte: IBGE 2010 e MINAS GERAIS, CBMMG, Plano de Comando 2021.

O Corpo de Bombeiros Militar de Minas Gerais se faz presente em 76 desses municípios (menos de $8 \%$ do total de cidades), atendendo diretamente mais de 10 milhões de habitantes (mais de $56 \%$ dos cidadãos), conforme gráfico 1 , pois está estrategicamente posicionado em cidades com muitos habitantes e cidades polos no território mineiro. 


\section{Gráfico 02 - População atendida pelo CBMMG em Minas Gerais}

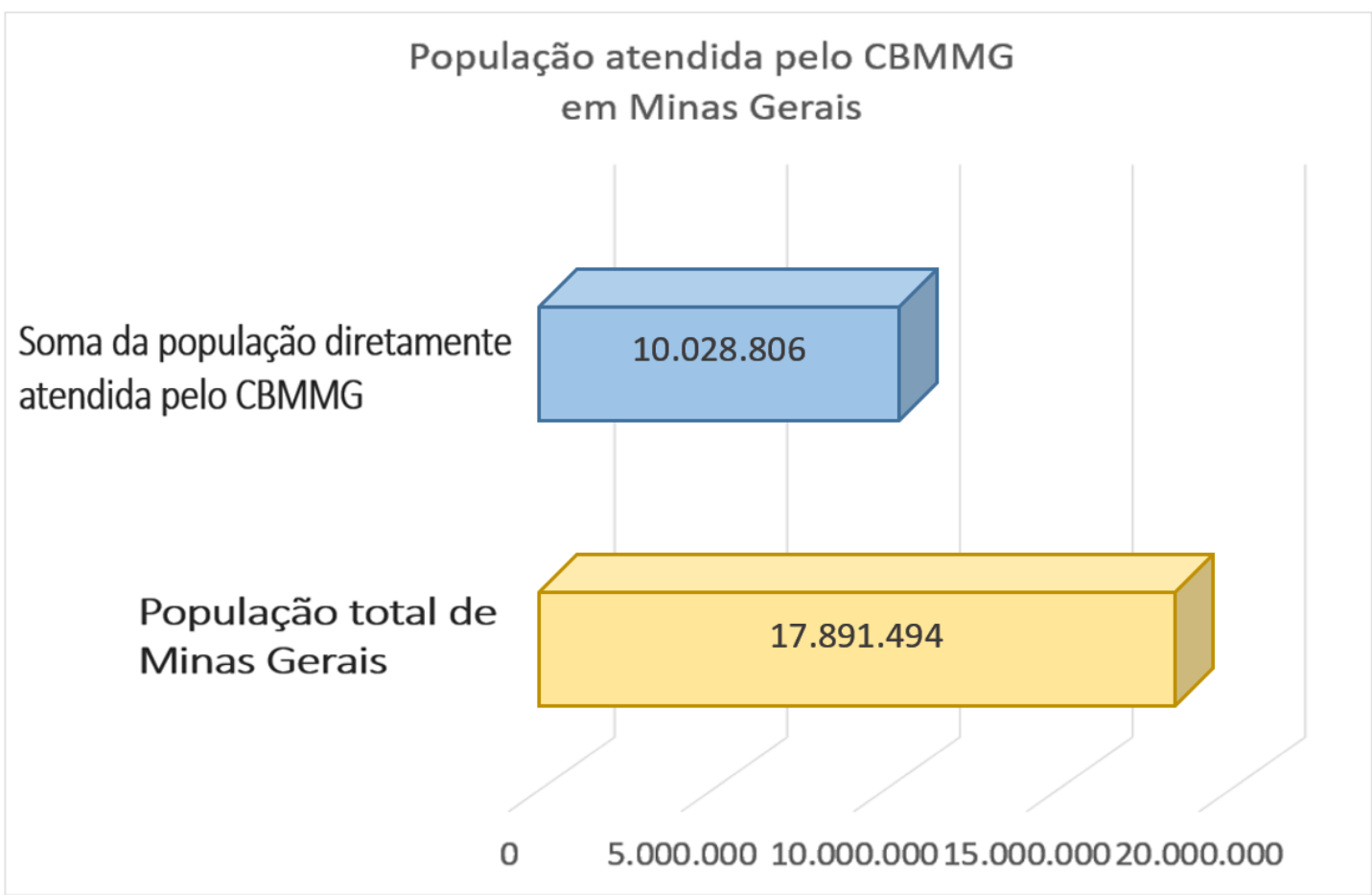

Fonte: IBGE 2010.

Verifica-se que a Constituição do Estado de Minas Gerais, no Capítulo II - Da Organização dos Poderes, Seção V Da Segurança do Cidadão e da Sociedade, Subseção II Da Segurança Pública, artigo 142, estabelece como competência do CBMMG:

[...] II - ao Corpo de Bombeiros Militar, a coordenação e a execução de ações de defesa civil, a prevenção e combate a incêndio, perícias de incêndio, busca e salvamento e estabelecimento de normas relativas à segurança das pessoas e de seus bens contra incêndio ou qualquer tipo de catástrofe [...] (MINAS GERAIS, 1989). (grifo nosso)

Claramente o legislador determina ao Corpo de Bombeiros Militar as tarefas coordenação e execução de PDC. No entanto, não há como afirmar, 
sendo a atuação do agente público tipicamente atuante nos municípios, que o legislador estadual determina ao Corpo de Bombeiros essa atribuição de responsabilidade sobre ações de Proteção e Defesa Civil, como na figura 3, afirmado pelo Eixo de Suporte 2, especialmente no Ciclo Completo de Proteção e Defesa:

Figura 3 - Eixo Suporte 2 do Plano de Comando.

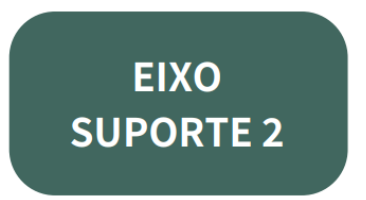

\section{Aumento da Resiliência aos Desastres}

\section{PROGRAMAS \\ SUPORTE}

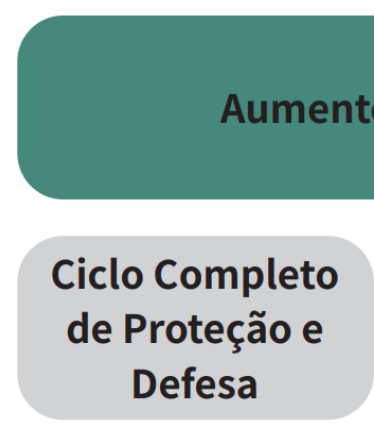

Cidades Mais

Resilientes

\section{Capacitação em \\ Proteção}

Fonte: MINAS GERAIS, CBMMG, Plano de Comando 2021.

Ainda no campo das leis estaduais em Minas Gerais, a Lei Complementar Estadual no 54, de 13 de dezembro de 1999, dispõe sobre a organização básica do CBMMG, definindo suas competências, dentre elas:

[...] Art. $3^{\circ}$ - Compete ao Corpo de Bombeiros Militar:

I - coordenar e executar as ações de defesa civil, proteção e socorrimento públicos, prevenção e combate a incêndio, perícias de incêndio e explosão em locais de sinistro, busca e salvamento; (grifo nosso)

$[\ldots]$

III - coordenar a elaboração de normas relativas à segurança das pessoas e dos seus bens contra incêndios e pânico e outras previstas em lei, no Estado;

$[\ldots]$

VI - exercer a supervisão das atividades dos órgãos e das entidades civis que atuam em sua área de competência;

VII - aprimorar os recursos humanos, melhorar os recursos materiais e buscar novas técnicas e táticas que propiciem segurança à população (MINAS GERAIS, 1999). (grifo nosso) 
Em 22 de setembro de 2014, o comando do CBMMG, através da Resolução do no 572 aprovou e instituiu o Plano Estratégico do Corpo de Bombeiros Militar de Minas Gerais. No ano de 2015 a Diretoria de Assuntos Institucionais (DAI) regulou as atividades referentes às ações de coordenação e execução do Planejamento Estratégico: "Objetivo Estratégico 02 - Estimular ações preventivas e proporcionar respostas eficientes aos desastres. Estratégia 01 - Estruturação de sistema de preparação, prevenção e respostas a desastres." (CBMMG, 2015). O item foi atualizado em no Plano de Comando em sua $4^{\mathrm{a}}$ edição apresentada pela Assessoria de Planejamento (ASPLAN) em 2021 com o Eixo Suporte 2 - Aumento da Resiliência aos Desastres, especialmente com o estabelecimento do programa de suporte "Ciclo Completo de Proteção e Defesa". Tem-se claramente uma política interna de transição de capacitação de mão de obra especializada para assumir as funções, conforme normas demonstradas, coordenação, direção e execução dos serviços de Proteção e Defesa Civil.

Atualmente o CBMMG possui 12 (doze) bombeiros militares cedidos à Coordenadoria Estadual de Defesa Civil, mas nenhum BM atua como assessor em nenhuma Coordenaria Municipal de Proteção e Defesa Civil.

\section{Tabela 1 - Efetivo do CBMMG versus efetivo CBMMG cedido às COMPDECs}

\begin{tabular}{l|c|c|c|c}
\multicolumn{2}{c|}{$\begin{array}{c}\text { EFETIVO } \\
\text { CBMMG }\end{array}$} & $\begin{array}{c}\text { CEDIDOS ÀS } \\
\text { COMPDECS }\end{array}$ & \multicolumn{2}{c}{$\begin{array}{c}\text { DESTINO DO } \\
\text { EFETIVO CBMMG }\end{array}$} \\
\cline { 4 - 5 } & CBMMG & COMPDECS \\
\hline Oficiais & 515 & 00 & $100,00 \%$ & $00,00 \%$ \\
\hline Praças & 5563 & 00 & $100,00 \%$ & $00,00 \%$
\end{tabular}

Fonte: MINAS GERAIS, CBMMG, Plano de Comando 2021e Almanaque de Oficiais 2021.

Sob a coordenação da Diretoria de Recursos Humanos (DRH), o CBMMG faz a cessão de 48 (quarenta e oito) bombeiros militares para atuarem como assessores militares em órgãos estaduais. 
Tabela 2 - Efetivo do CBMMG cedido à órgãos estaduais.

\begin{tabular}{l|c|c|c|c}
\multicolumn{2}{c|}{$\begin{array}{c}\text { EFETIVO } \\
\text { CBMMG }\end{array}$} & $\begin{array}{c}\text { CEDIDOS À } \\
\text { ÓRGÃOS } \\
\text { ESTADUAIS }\end{array}$ & \multicolumn{2}{c}{$\begin{array}{c}\text { DESTINO DO } \\
\text { EFETIVO CBMMG }\end{array}$} \\
\cline { 4 - 5 } & CBMMG & $\begin{array}{c}\text { ÓRGÃOS } \\
\text { ESTADUAIS }\end{array}$ \\
\hline Oficiais & 515 & 10 & $99,84 \%$ & $0,16 \%$ \\
\hline Praças & 5563 & 38 & $99,38 \%$ & $0,62 \%$
\end{tabular}

Fonte: MINAS GERAIS, CBMMG, Plano de Comando 2021e Almanaque de Oficiais 2021.

Toda a capacidade laboral dos nobres soldados do fogo é forjada nas escolas de formação profissional, que no CBMMG acontecem intramuros sob supervisão da Academia de Bombeiro Militar (ABM). Para tanto, a ABM cumpre os requisitos determinados nas resoluções de ensino diversas e em especial as resoluções que versam sobre as grades obrigatórias para os cursos de formação - seja de praças, seja de oficiais.

Como destacada ação em prevenção, podemos identificar que no "VII vistoriar edificações e áreas de risco e promover, quando for o caso, a intervenção preventiva e a evacuação da população das áreas de alto risco ou das edificações vulneráveis" do art $8^{\circ}$ da Lei 12.608 , este serviço já é prestado pelo CBMMG em sua atuação sob a ótica da Lei 14.130 de 19/12/2001, que dispõe sobre a prevenção contra incêndio e pânico no Estado de Minas Gerais.

Ainda como outro exemplo sobre a atuação dos bombeiros militares em ações de proteção e defesa civil nos municípios, destaca-se a grande quantidade de atendimentos que são classificados como no grupo $Q$ da Diretriz Integrada de Ações e Operações do Sistema de Defesa Social de Minas Gerais (DIAO) - demonstrações, palestras e treinamentos - como pode-se verificar na tabela 3: 
Revista Científica do Corpo de Bombeiros Militar de Pernambuco

Artigo Publicado no Vol.07 N.19 - Julho a Dezembro 2021 - ISSN 2359-4829

Versão on-line disponível em: http://www.revistaflammae.com

Tabela 3 - Quantidade de atendimento de ocorrências do Grupo Q demonstrações, palestras e treinamentos

\begin{tabular}{c|c|c} 
GRUPO DIAO & ANO & $\begin{array}{c}\text { ATENDIMENTOS } \\
\text { / REDS }\end{array}$ \\
\hline \multirow{4}{*}{$\begin{array}{c}\text { Q - demonstrações, palestras e } \\
\text { treinamentos }\end{array}$} & 2015 & 7.178 \\
\cline { 2 - 3 } & 2016 & 10.469 \\
\cline { 2 - 3 } & 2017 & 14.266 \\
\cline { 2 - 3 } & 2018 & 19.626 \\
\cline { 2 - 3 } & 2019 & 17.518 \\
\cline { 2 - 3 } & 2020 & 15.965
\end{tabular}

Fonte: compilado intranet - PowerBI Série Histórica dos Atendimentos CBMMG

Para melhor expor o problema, suas causas, consequências, bem com propor meios ou caminhos para atingir objetivos e buscar soluções, inicia-se esta etapa com o primeiro ponto: a identificação clara do problema, que para este estudo foi assim definido:

\section{Tabela 4 - Problema na Árvore de Problemas}

\section{ÁRVORE DE PROBLEMAS}
Problema operacional e de desastres, bem como de riscos coletivos nos municípios.

Fonte: o autor.

Neste estudo, alguns itens apontados podem ser identificados como causas do problema, pois mais de $50 \%$ das COMPDECs não possuem quadro de funcionários de carreira. Os números de treinamentos, demonstração e palestras podem ser verificados em elevação, mas não objetivaram diminuição de desastres, pois não há bombeiros militares nas COMPDECs assim não há direta relação nas políticas e estratégias de prevenção. Também há 
Revista Científica do Corpo de Bombeiros Militar de Pernambuco

Artigo Publicado no Vol.07 N.19 - Julho a Dezembro 2021 - ISSN 2359-4829

Versão on-line disponível em: http://www.revistaflammae.com

necessidade de mais investimentos na prevenção, como apontado pelo Marco de Sendai, como sugerido na figura abaixo:

\section{Figura 4 - Árvore de problemas}

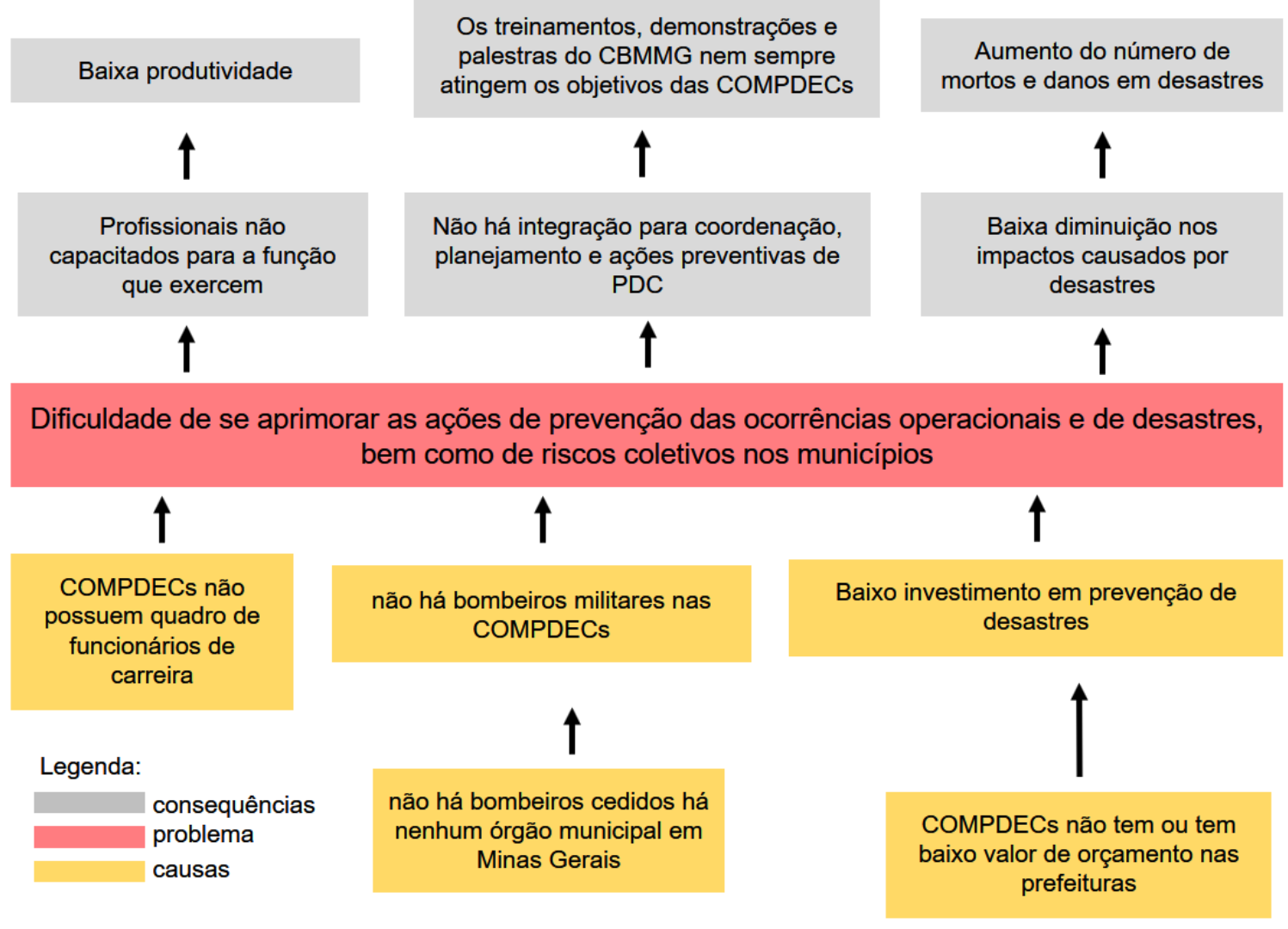

Fonte: o autor.

Então, o problema "dificuldade de se aprimorar as ações de prevenção de ocorrências operacionais e de desastres, bem como de riscos coletivos no municípios" se apresentou baseada nas causas de falta de logística, falta de recursos humanos, falta de recursos financeiros. O resultado final vislumbrado foi a baixa produtividade, os treinamento não atingindo os objetivos propostos e com desdobramento em possível aumento do número de mortos e danos em desastres. 
Revista Científica do Corpo de Bombeiros Militar de Pernambuco

Artigo Publicado no Vol.07 N.19 - Julho a Dezembro 2021 - ISSN 2359-4829

Versão on-line disponível em: $\underline{\text { http://www.revistaflammae.com }}$

Com o problema identificado, passou-se ao estabelecimento da "árvore de objetivos" para buscar definir causas e impactos. A grande maioria das COMPDECs não tem em seu quadro pessoal especializado na área de atuação, o que diminui a capacidade operativa do órgão. Já o CBMMG treina e capacita seus bombeiros para atuarem em Proteção e Defesa Civil, mas nenhum bombeiro militar está atualmente destacado como assessor militar em nenhuma COMPDEC no Estado de Minas Gerais. O objetivo deve ser diametralmente oposto ao problema apresentado, assim, pode-se listar como causa e falta de profissionais capacitados para ações de coordenação, planejamento e implementação de ações de prevenção em Proteção e Defesa Civil.

Figura 5 - Árvore de objetivos

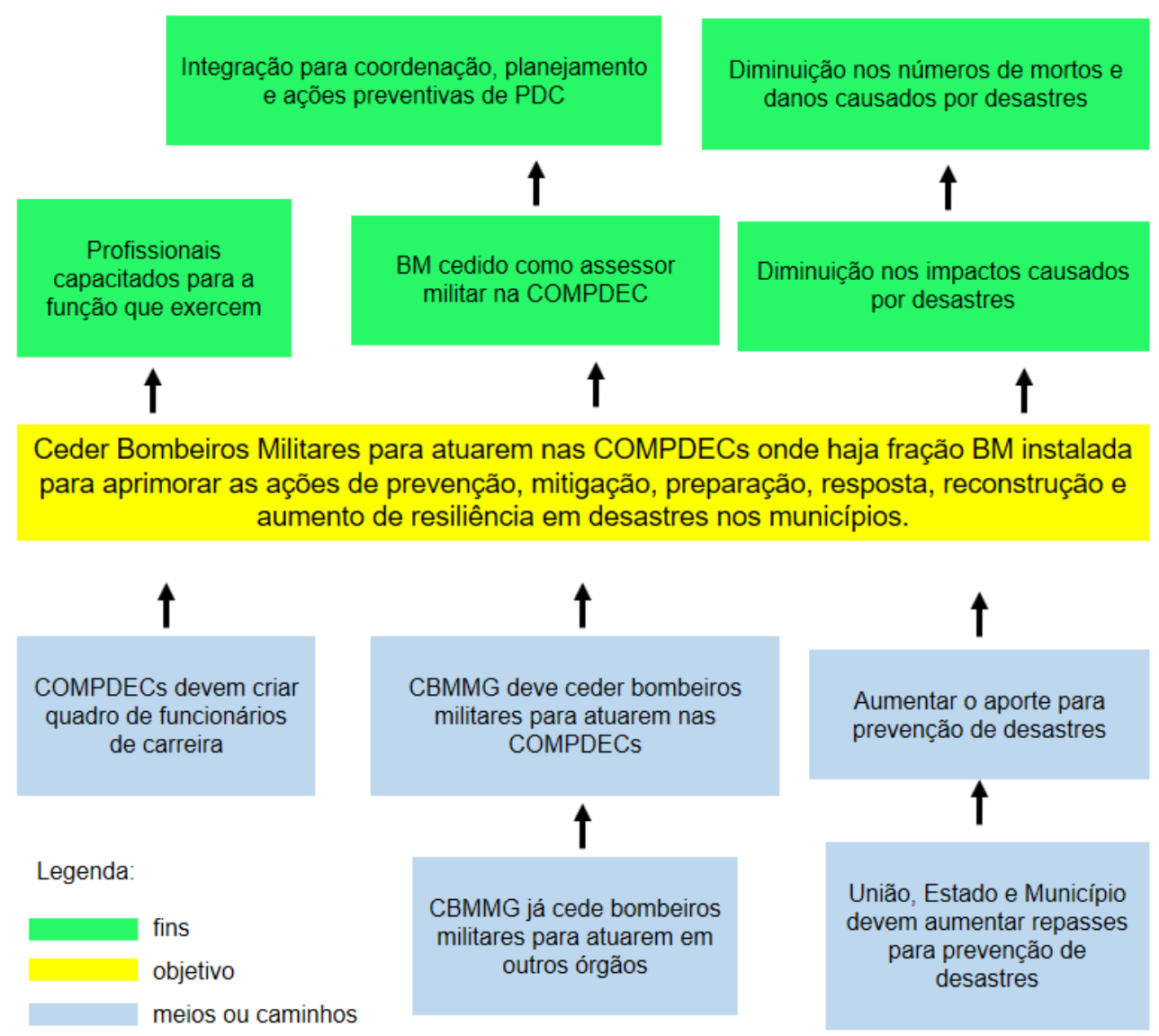

Fonte: o autor. 
Uma das formas para cumprir o determinado no PMDI 2016-2027 foi o desdobramento no Plano de Comando 2015-2016 do CBMMG, em sua $4^{\text {a }}$ Edição no ano de 2021, em seu Eixo de Suporte 2, que apresenta como programa suporte o Ciclo Completo de Proteção e Defesa. Buscando soluções dentro das viáveis e possíveis pelo CBMMG para enfrentar o problema de estar longe da comunidade em ações de prevenção de desastres, foi identificado que o órgão de governo mais próximo da comunidade é o município. Através de sua Coordenadoria Municipal de Proteção e Defesa Civil (que faz ações tipicamente de bombeiro militar) deveria tomar providências eficazes para diminuir os impactos dos desastres: quando acontece o não cumprimento deste item abre-se uma lacuna e uma oportunidade ao CBMMG que, já possuindo mão de obra qualificada para essa missão, pode cumprir suas metas constitucionais, aumentar sua presença de forma local/municipal e ajudar a comunidade:

\section{Tabela 5 - Objetivo do Projeto}

\section{MATRIZ DO MARCO LÓGICO}

\begin{tabular}{c|c}
$\begin{array}{c}\text { Objetivo do } \\
\text { Projeto }\end{array}$ & $\begin{array}{c}\text { Ceder Bombeiros Militares para atuarem nas COMPDECs } \\
\text { onde haja fração BM instalada para aprimorar as ações de } \\
\text { prevenção, mitigação, preparação, resposta, reconstrução e } \\
\text { aumento de resiliência em desastres nos municípios. }\end{array}$
\end{tabular}

Fonte: o autor.

A distribuição de cessão de bombeiros militares para atuarem nas COMPDECs como finalidade deste estudo então é apresentada desta maneira: 
Tabela 6 - Distribuição de efetivo BM para cessão às COMPDECs

\begin{tabular}{l|c|c}
\multicolumn{1}{c|}{ MUNICíPIO } & $\begin{array}{c}\text { POSTO/ } \\
\text { GRADUAÇÃo }\end{array}$ & $\begin{array}{c}\text { QUANTIDADE } \\
\text { TOTAL }\end{array}$ \\
\hline $\begin{array}{l}\text { Sedes de Batalhões: Belo Horizonte, Contagem, } \\
\text { Juiz de Fora; Governador Valadares, Montes Claros, } \\
\text { Uberlândia, Uberaba, Varginha, Divinópolis, Ipatinga } \\
\text { e Patos de Minas. }\end{array}$ & MAJOR & 11 \\
\hline $\begin{array}{l}\text { Sedes de Companhias Independentes: Poços de } \\
\text { Caldas, Barbacena, Diamantina e Sete Lagoas }\end{array}$ & CAPITÃO & 5 \\
\hline $\begin{array}{l}\text { Sedes de Companhia: Ouro Preto, Araxá, Ubá, } \\
\text { Araguari, Unaí, Teófilo Otoni, Manhuaçu, Lavras, }\end{array}$ & TENENTE & \multirow{2}{*}{12} \\
$\begin{array}{l}\text { Pará de Minas, Passos, Alfenas e Conselheiro } \\
\text { Lafaiete. }\end{array}$ & \\
\hline $\begin{array}{l}\text { Sedes de Pelotão / Postos Avançados: Ponte Nova, } \\
\text { Juatuba, Sete Lagoas, Ribeirão das Neves, }\end{array}$ & \\
$\begin{array}{l}\text { Vespasiano, Sabará, Nova União, Muriaé, Viçosa, } \\
\text { Leopoldina, Muriaé, Ituiutaba, Janaúba, Januária, }\end{array}$ & \\
$\begin{array}{l}\text { Pirapora, Curvelo, Araxá, Frutal, Iturama, Campos } \\
\text { Altos, Itajubá, Extrema, Três Corações, São }\end{array}$ & \\
Lourenço, Oliveira, Itaúna, Nova Serrana, São \\
Sebastião do Paraíso, Piumhi, Guaxupé, São João \\
Del Rei, Manhuaçu, Coronel Fabriciano, Itabira, \\
$\begin{array}{l}\text { Timóteo, Caratinga, Unaí, Patrocínio, Paracatu, } \\
\text { Betim, Lagoa Santa, Arcos, Além Paraíba, Francisco } \\
\text { Sá, São João Evangelista e Boa Esperança. }\end{array}$
\end{tabular}

Fonte: o autor. 


\section{CONCLUSÃO}

Portanto, verifica-se que a possibilidade do CBMMG se fazer presente no municípios pode atender a uma importante demanda dos grandes órgãos de doutrina de prevenção e diminuição de riscos de desastres: além de estreitar os laços com órgãos municipais através de convênios, ceder bombeiros militares para atuarem nas Coordenadorias Municipais de Proteção e Defesa Civil é um caminho para inovação produtiva e para o aumento da resiliências nas comunidades. Espera-se a diminuição dos impactos dos desastres através de prevenção, seja com redução do número de mortos e feridos, seja com redução no impacto financeiro nas vidas das pessoas, das empresas e da cidade.

Para tanto, cabe ao Corpo de Bombeiros Militar de Minas Gerais operacionalizar a cessão de 76 bombeiros militares, que para a corporação são apenas $1,25 \%$ de seu efetivo, mas serão $100 \%$ de bombeiros nas COMPDECs onde haja fração BM instalada.

Assim os atuais 48 bombeiros cedidos à órgãos de estado representam $0,78 \%$ do efetivo e os 76 BM sugeridos a serem cedidos aos municípios são $1,25 \%$ da tropa no estado. Juntos, alcançariam um total de 124 bombeiros, com a equivalência de $2,04 \%$ de toda a tropa disponível do CBMMG, mostrando um pequeno impacto no efetivo e custos de salários que podem ser até mesmo desprezados frente ao grande impacto positivo na prevenção e ações de mitigação com gestão proativa de Proteção e Defesa Civil. 


\section{REFERENCIAS}

BRASIL. Lei № 12.608, de 10 de abril de 2012. Institui a Política Nacional de Proteção e Defesa Civil - PNPDEC; dispõe sobre o Sistema Nacional de Proteção e Defesa Civil - SINPDEC e o Conselho Nacional de Proteção e Defesa Civil - CONPDEC; e dá outras providências. Brasília, 2012.

CASSIOLATO, Martha. GUERESI. Como elaborar Modelo Lógico: roteiro para formular programas e organizar avaliação. Nota 06 IPEA. Brasília, setembro de 2010. Disponível em < http://www.ipardes.gov.br/pdf/multissetorial/nota_tecnica_IPEA.pdf $>$. Acessado em 30 de setembro de 2021.

CEPED/RS - Centro Universitário de Estudos e Pesquisas sobre Desastres. Capacitação em Gestão de Risco de Desastres. Porto Alegre: CEPED/UFRGS, 2014. 257p.

LONDE, L. R.; SORIANO, E.; COUTINHO, M. P. Capacidades das instituições municipais de proteção e defesa civil no brasil: desafios e perspectivas. Revista do Departamento de Geografia - USP, Volume 30 (2015), p. 77 a 95. Disponível em https://tinyurl.com/ycryqdzz. Acessado em 10 out 2016.

MINAS GERAIS. Corpo de Bombeiros Militar. Plano de Comando 2015 2026. Belo Horizonte: Comando Geral, 4를 Edição, 2021.

MINAS GERAIS. Plano Mineiro de Desenvolvimento Integrado 2016-2027. Disponível em < https://www.mg.gov.br/conteudo/transicao/pmdi/pmdi>. Acesso em 30 de setembro de 2021. 
PAZ, Caroline Lima. PICININ, Cláudia de Carvalho. Cessão de servidor público: uma análise com enfoque nas decisões proferidas pelo TCEMG e pelo TJMG. Revista TCEMG jan-fev-mar 2014. Disponível em < https://docplayer.com.br/1551278-Cessao-de-servidor-publico-uma-analisecom-enfoque-nas-decisoes-proferidas-pelo-tcemg-e-pelo-tjmg.html>. Acessado em 30 de setembro de 2021.

PFEIFFER, Peter. 0 quadro lógico: um método para planejar e gerenciar mudanças. Revista do Serviço Público, Brasília, ano 51, n. 1, jan-mar 2000, pp. 81 - 122.2 Disponível em: $<$ http://seer.enap.gov.br/index.php/RSP/article/view/320>. Acesso em $30 \mathrm{de}$ setembro de 2021.

RUA, Maria das Graças. A aplicação prática do marco lógico. Brasília: Escola Nacional de Administração Pública, S.D. Disponível em: $<$ http://antigo.enap.gov.br/downloads lec43ea4fAvaliacao_pratica_marco_logico.pdf>. em 30 de setembro de 2021.

SAADI, Allaoua. A geomorfologia da serra do espinhaço em Minas Gerais e de suas margens. Revista Geonomos, Volume 3 nr 1. 1995. Disponível em < http://igc.ufmg.br/portaldeperiodicos/index.php/geonomos/article/view/215 >. Acessado em em 30 de setembro de 2021.

UN-ISDR - International Strategy for Disaster Reduction. 2015. Sendai Framework for Disaster Risk Reduction 2015 - 2030. Disponível em https://www.unisdr.org/files/43291_63575sendaiframeworkportunofficialf\%5B1 \%5D.pdf Acesso em 30 de setembro de 2020. 